\title{
Gastrostomies in Older Patients: The 1990 National Hospital Discharge Survey
}

\author{
Mark D. Grant, MD, MPH
}

Background: Although many published case series have described patients' experiences after gastrostomy placement, generalizing from the results of case series can present problems. The purpose of this study was to examine gastrostomy placement among hospitalized older patients in a nationally representative sample.

Methods: Using the 1990 National Hospital Discharge Survey, age, sex, race, primary and secondary diagnoses, and mortality were described for hospitalized patients aged 65 years and older having gastrostomies. Age-specific placement rates were calculated using mid-1990 Census Bureau population estimates.

Results: In 1990 an estimated 85,400 patients aged 65 years and older were discharged from hospitals with gastrostomies. Frequent primary diagnoses included cerebrovascular disease (19 percent), pneumonia with or without aspiration (12 percent), neoplasm (11 percent), and fluid and electrolyte disorders ( 9 percent). The in-hospital mortality rate was 16 percent. Age-specific rates for gastrostomy increased from 1.2 per 1000 for those aged 65 to 74 years to 10.8 per 1000 for those aged 85 years and older.

Conclusions: In 1990 older hospitalized patients had gastrostomies with surprising frequency, and their in-hospital mortality rate was substantial. An estimated 1 percent of the US population aged 85 years and older was discharged from a hospital in 1990 with a gastrostomy. (J Am Board Fam Pract 1998;11:187-92.)

The use of feeding tubes for older patients provokes considerable debate over ethical ${ }^{1-5}$ and quality-of-life ${ }^{6,7}$ concerns. Few population-based descriptive data exist, however, regarding the use of gastrostomies in older patients. Although many have described experiences from selected patient samples, particularly with percutaneous gastrostomy placement and follow-up, generalizing those results can be problematic.

The use of gastrostomies in the growing elderly population is important to examine for several reasons. First, the introduction in the early 1980s of percutaneous endoscopic gastrostomy $(\mathrm{PEG})^{8}$ might have led to increasing gastrostomy placement in older patients. According to the $\mathrm{Na}$ tional Hospital Discharge Survey (NHDS), between 1988 and 1993 the number of patients aged 65 years and older who had gastrostomies increased from approximately $61,000^{\circ}$ to $108,000 .^{10}$ Furthermore, in 1993 an estimated 83,000 pa-

Submitted 24 July 1997.

From the Vest Suburban Hospital Family Practice Residency, Oak Park, III. Address reprint requests to Mark D. Grant, MD, MPH, West Suburban Center for Primary Care, 7411 WV. Lake St, River Forest, IL 60305.

This paper was presented in part at the $52 \mathrm{nd}$ annual meeting of the American Geriatrics Society, Washington, DC, 1995. tients had PEGs ${ }^{10}$ (procedure coding before 1990 does not allow comparably distinguishing PEGs from gastrostomies inserted operatively). Second, describing the characteristics and outcomes for older patients enterally fed by gastrostomy should lead to a more informed decision when considering gastrostomy placement. Finally, while patients having gastrostomies are often compromised, the intent is usually long-term feeding; how frequently do older patients with gastrostomies fail to survive hospitalization?

To provide a basis for exploring these issues, this study describes gastrostomy use in a nationally representative sample of older patients using the 1990 NHDS. ${ }^{11}$

\section{Methods}

The NHDS is a nationwide survey of patients discharged from noninstitutional short-stay hospitals in the 50 states, excluding all federal, military, and Veterans Administration institutions. " The 1990 NHDS data were collected from 474 hospitals; the complex sample design of the survey allows estimating national frequencies for diagnoses, procedures, and mortality. Up to seven diagnoses and four procedures were recorded for each discharge. Diagnoses are listed in the order recorded on abstract forms, except acute myocardial infarction, 
Table 1. Characteristics of Older Patients With Gastrostomies, 1990 National Hospital Discharge Survey.

\begin{tabular}{lcc}
\hline Characteristics & Number $^{*}$ & $\begin{array}{c}\text { Rate per } 1000 \\
\text { Population }\end{array}$ \\
\hline Age, years & & 1.2 \\
$65-74$ & 21,000 & 3.1 \\
$75-84$ & 31,600 & 10.8 \\
85 and older & 32,800 & 2.5 \\
Sex & & 2.9 \\
Male & 31,500 & \\
Female & 53,800 & 2.1 \\
Race & & 4.7 \\
White & 58,900 & - \\
African-American & 11,700 & 2.7 \\
Not stated or other & 14,700 & \\
Total & 85,400 & \\
\hline
\end{tabular}

${ }^{*}$ Rounded to the nearest hundred.

tNumber of gastrostomies divided by mid-1990 census estimates for age-, race-, and sex-specific subgroups.

${ }^{\ddagger}$ Numbers will not sum to total because of rounding.

which is always considered the primary diagnosis. For the less than 2 percent of discharges for which age and sex were not recorded, both were imputed based on patients with similar diagnostic profiles. ${ }^{11}$

Procedures coded according to the International Classification of Diseases, 9th Revision, Clinical Modification (ICD-9-CM) ${ }^{12}$ as percutaneous gastrostomy (ICD-9-CM 43.11) or other gastrostomies (ICD9-CM 43.19) were combined for analysis. Because of the complex sampling scheme, population projections or estimates are subject to error, particularly when based on few discharges. Accordingly, when the sample size (not the weighted or population projection) numbered fewer than 30 , the population estimate is not reported because of possible error. ${ }^{11}$ For sample sizes numbering between 30 and 59 , the estimate is reported but reliability cannot be assumed and is accordingly noted. ${ }^{11} \mathrm{Be}-$ cause there were few deaths in some subgroups (ie, fewer than 30), only the overall in-hospital mortality rate was calculated. Additionally, estimatesbeing approximate-were rounded to the nearest 100 , and percentages to whole numbers. For reference, the total unweighted sample size was 655 .

Summary diagnostic categories were grouped according to the classification scheme described by Elixhauser et al, ${ }^{13}$ with a category added for swallowing disorders (ICD-9-CM 787.2 [dysphagia], 783.3 [feeding difficulties], V41.6 [problems with swallowing and mastication]). Finally, ap-

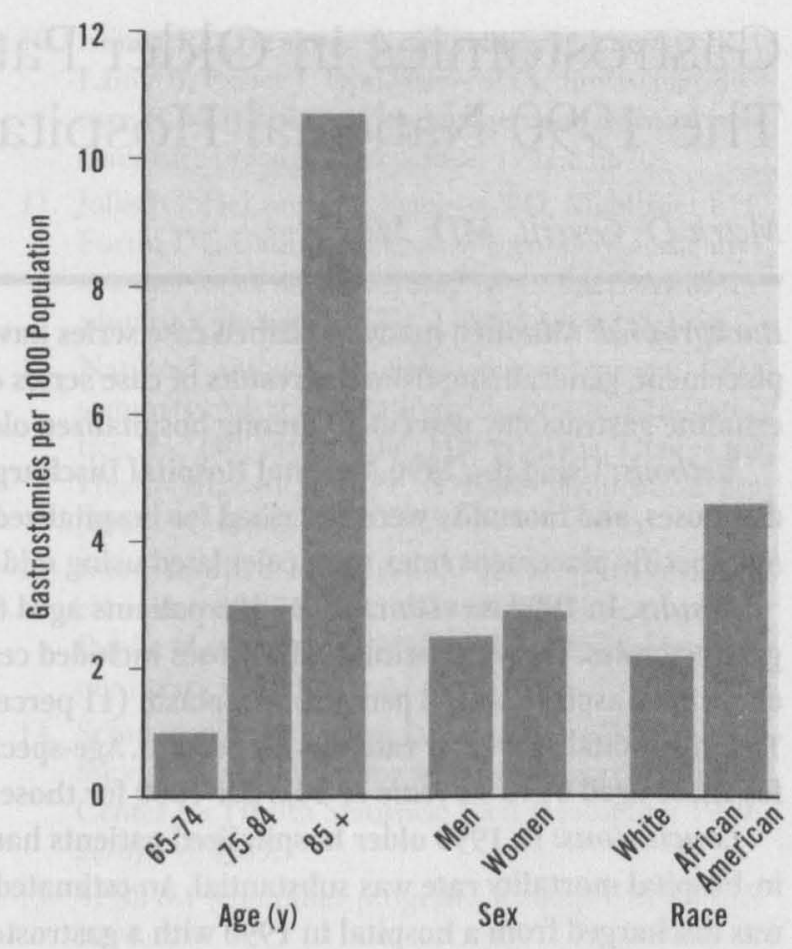

Figure 1. Bar heights represent number of gastrostomies placed per 1000 population according to age, race, and sex subgroups. Denominators from mid-1990 census estimates were used to calculate placement rates.

proximate age-specific rates per 1000 population for gastrostomy placement were calculated using denominators obtained from mid-1990 Census Bureau estimates.

\section{Results}

According to the NHDS, in 1990 approximately 85,400 patients aged 65 years and older were discharged from the hospital with gastrostomies (Table 1). Sixty-six percent of the gastrostomies were recorded as PEGs, the remainder as operatively inserted gastrostomies. The estimated inhospital mortality was 16 percent. Approximately 2.7 gastrostomies were placed per 1000 persons aged 65 years and older living in the United States in 1990. Age-specific placement rates increased from $1.2 / 1000$ for patients aged 65 to 74 years to $10.8 / 1000$ for those aged 85 years and older (Table 1 and Figure 1). Placement rates were greater among women than men; the rate among African Americans was more than twice that of whites.

The most frequent primary diagnoses were cerebrovascular disease (19 percent), pneumonia (12 percent), neoplasm (11 percent), and fluid and electrolyte disorders (Table 2). A primary or sec- 
ondary fluid and electrolyte disorder diagnosis was recorded in 46 percent of discharges, and a nutritional deficiency in 25 percent. As expected, common secondary diagnoses (Table 2) included fluid and electrolyte disorders, urinary tract infections, nutritional deficiencies, cerebrovascular disease, pneumonia, diabetes, and congestive heart failure. One in 5 patients had dementia recorded as a primary or secondary diagnosis.

Probable common indications for gastrostomy placement from listed primary and secondary diagnoses would include swallowing disorders, nutritional deficiencies, aspiration pneumonia, or pharyngeal, laryngeal, and esophageal neoplasms. ${ }^{14}$ Yet, less than one half of patients having gastrostomies (42 percent) had at least one of these diagnoses listed among the seven possibly recorded.

Finally, more than one half ( 55 percent) of these older patients surviving hospitalization were discharged to long-term care, although the proportion of patients so discharged varied by age: 61 percent of those aged 75 years and older, but 34 percent of those aged 65 to 74 years.

\section{Discussion}

Investigators have reported a variety of patient experiences following gastrostomy insertion in older patients, with 30 -day mortality rates varying from 0 to 30 percent or more. Studies conducted since $1980^{15-65}$ suggest that the risk of short-term mortality is high, though when trying to generalize their results, problems arise: patient selection criteria differ considerably, and the length of followup varies from study to study. The strength of the NHDS is that it provides nationally representative data with demographic and diagnostic information as well as in-hospital mortality.

The results obtained from the 1990 NHDSthe substantial in-hospital mortality rate and the array of primary and secondary diagnoses-suggest that the older hospitalized patients having gastrostomies were compromised. Placement rates were highest among those aged 85 and older, women, and African Americans. Surprisingly, these data indicate that in 1990 approximately 1 of every 100 persons aged 85 years and older living in the United States was discharged from a hospital with a gastrostomy. While the higher placement rate among women is consistent with their longer survival, it is more difficult to explain the more than twofold increased rate among African Americans
Table 2. Percentage of Frequent Primary and Secondary Diagnoses Among Older Patients With Gastrostomies, 1990 National Hospital Discharge Survey.

\begin{tabular}{ll}
\hline Diagnoses & Percent of Total \\
\hline
\end{tabular}

Primary diagnoses

Cerebrovascular disease $\quad 19$

Pneumonia $\quad 12$

Neoplasm 11

Fluid or electrolyte disorder $\quad 9$

Secondary diagnoses

Fluid or electrolyte disorder $\quad 37$

Urinary tract infection $\quad 25$

Nutritional deficiency $\quad 21$

Dementia $\quad 18$

Cerebrovascular disease $\quad 17$

Pneumonia $\quad 17$

Diabetes 16

Congestive heart failure $\quad 13$

Chronic obstructive pulmonary disease $\quad 12$

Ischemic heart disease $\quad 12$

Neoplasm 11

Decubitus ulcer 11

Swallowing disorders $\quad 11$

Intestinal disorders ${ }^{*} \quad 8$

Respiratory failure* $\quad 6$

Complications $\quad 5$

Sepsis* 4

Esophageal disorders* 4

From a projected $10,333,000$ discharges among patients aged 65 years and older.

${ }^{*}$ Sample size was between 30 and 59, and estimate might not be reliable.

compared with whites. The Hospital Cost and Utilization Project found that in 1987 African Americans had gastrostomies placed at a rate almost twice that of whites. ${ }^{66}$ The racial disparity could be due to differences in stroke risk ${ }^{67}$ or attitudes toward life-sustaining therapies. ${ }^{68}$ Yet one must also note that the accuracy with which race was recorded in the NHDS has been questioned when considering these differences. ${ }^{69}$

Interestingly, dementia was listed as a primary or secondary diagnosis in 20 percent of patients. Because dementia as a discharge diagnosis lacks both sensitivity and specificity ${ }^{70}$ however, the true proportion might be higher or lower. Whereas the diagnostic coding of dementia subsets could not be examined due to small sample sizes, the high prevalence of cerebrovascular disease suggests that vascular dementias might have been overrepresented in the sample. ${ }^{71}$ 
Although determining indications for gastrostomy placement from discharge data is potentially difficult, listed diagnoses nevertheless contain considerable information. Consistent with suggested indications for a PEG, ${ }^{14}$ nutritional deficiencies, inability to swallow, aspiration with pneumonia, or pharyngeal, laryngeal, and esophageal neoplasms are the most apparent reasons for gastrostomy placement. Yet one of these diagnoses was listed for fewer than one half of patients. Although it is possible that poor diagnostic coding by physicians and hospital personnel account for the low number of these diagnoses, it is more curious that only one quarter of patients had a nutritional deficiency diagnosis. Perhaps nutritional deficiencies occurred in almost all patients, yet they were not diagnosed. ${ }^{72}$ The diagnosis might also not have been retrievable because the number of diagnoses exceeded the seven allotted fields in the NHDS files ( 39 percent of patients had seven recorded diagnoses).

Although the strength of the NHDS is the representativeness of the sample and the ability to calculate national rates, this study has limitations. First, only the overall in-hospital mortality can be reliably estimated. Second, we did not assess the use of nasogastric feeding tubes. Among patients who had a nasogastric feeding tube preceding a gastrostomy, the nasogastric tube could have caused either morbidity or even death. Lastly, administrative discharge data obtained from the NHDS do not contain sufficient clinical detail to allow examining potential predictors of mortality or to analyze morbidity.

Still, some have questioned whether enteral feeding by gastrostomy prolongs life. ${ }^{73}$ The risk of aspiration accompanying nasogastric and PEG feedings could be similar, ${ }^{74}$ with jejunostomy possibly required to prevent aspiration. ${ }^{75}$ The potential complications and the high mortality rate among patients with gastrostomies have caused some to suggest that a permanent feeding tube be deferred unless survival seems probable. ${ }^{76}$ For practitioners, results obtained from the NHDS appear to support that view. Furthermore, that the PEG procedure is readily available and often well tolerated does not mean the clinical and ethical consequences of its use should not be carefully considered.

In conclusion, the 1990 NHDS data show many gastrostomies placed among older patients with a considerable in-hospital mortality rate. While enteral feeding by gastrostomy might be life-sustaining for some, for others it could have little benefit. Although these data do not indicate which patients would benefit, some questions must be raised regarding the increasing use of gastrostomies among older patients.

\section{References}

1. Olins NJ. Feeding decisions for incompetent patients. J Am Geriatr Soc 1986;34:313-7.

2. Campbell-Taylor I, Fisher RH. The clinical case against tube feeding in palliative care of the elderly. J Am Geriatr Soc 1987;35:1100-4.

3. Smith DG, Wigton RS. Modeling decisions to use tube feeding in seriously ill patients. Arch Intern Med 1987;147:1242-5.

4. Steinbrook R, Lo B. Artificial feeding - solid ground, not a slippery slope. N Engl J Med 1988;318:286-90.

5. McNabney MK, Beers MH, Siebens H. Surrogate decision-makers' satisfaction with the placement of feeding tubes in elderly patients. J Am Geriatr Soc 1994;42:161-8.

6. Quill TE. Utilization of nasogastric feeding tubes in a group of chronically ill, elderly patients in a community hospital. Arch Intern Med 1989;149:1937-41.

7. Weaver JP, Odell P, Nelson C. Evaluation of the benefits of gastric tube feeding in an elderly population. Arch Fam Med 1993;2:953-6.

8. Gauderer MW, Ponsky JL, Izant RJ Jr. Gastrostomy without laparotomy: a percutaneous endoscopic technique. J Pediatr Surg 1980;15:872-5.

9. Graves EJ. Detailed diagnoses and procedures. $\mathrm{Na}$ tional Hospital Discharge Survey, 1988. Vital Health Stat 13 1991;Mar(107):1-239.

10. Graves EJ. Detailed diagnoses and procedures. $\mathrm{Na}-$ tional Hospital Discharge Survey, 1993. Vital Health Stat 13 1995;Oct(122):1-288.

11. Graves EJ. Detailed diagnoses and procedures. National Hospital Discharge Survey 1990. Vital Health Stat 13 1992 Jun(113):1-225.

12. International classification of diseases, 9 th revision, clinical modification. 2nd ed. Washington, DC: Public Health Service, Health Care Financing Administration, 1980.

13. Elixhauser A, Andrews RM, Fox SH. Clinical classifications for health policy research: discharge statistics by principal diagnosis and procedure. Rockville, Md: Department of Health and Human Services, Public Health Service, Agency for Health Care Policy and Research, 1993. (AHCPR publication no. 93-0043.)

14. American Society for Gastrointestinal Endoscopy. The role of percutaneous endoscopic gastrostomy in enteral feeding. Guidelines for clinical application. Gastrointest Endosc 1988;34(3 Suppl):35S-6S. 
15. Pomerantz MA, Salomon J, Dunn R. Permanent gastrostomy as a solution to some nutritional problems in the elderly. J Am Geriatr Soc 1980;28:104-7.

16. Swartzendruber FD, Laws HL. The superior feeding gastrostomy. Am Surg 1982;48:276-8.

17. Wilkinson WA, Pickleman J. Feeding gastrostomy: a reappraisal. Am Surg 1982;48:273-5.

18. Russell TR, Brotman M, Norris F. Percutaneous gastrostomy: a new simplified and cost-effective technique. Am J Surg 1984;148:132-7.

19. Hinsdale JG, Lipkowitz GS, Pollock TW, Hoover $\mathrm{EL}, \mathrm{Jaffe} \mathrm{BM}$. Prolonged enteral nutrition in malnourished patients with nonelemental feeding. Reappraisal of surgical technique, safety, and costs. Am J Surg 1985;149:334-8.

20. Kirby DF, Craig RM, Tsang TK, Plotnick BH. Percutaneous endoscopic gastrostomies: a prospective evaluation and review of the literature. JPEN J Parenter Enteral Nutr 1986;10:155-9.

21. Miller RE, Kummer BA, Tiszenkel HI, Kotler DP. Percutaneous endoscopic gastrostomy. Procedure of choice. Ann Surg 1986;204:543-5.

22. Moore JP, Curreri PW, Rodning CB. Percutaneous endoscopic gastrostomy. Am Surg 1986;52:495-9.

23. Ruge J, Vazquez RM. An analysis of the advantages of Stamm and percutaneous endoscopic gastrostomy. Surg Gynecol Obstet 1986;162:13-6.

24. Stern JS. Comparison of percutaneous endoscopic gastrostomy with surgical gastrostomy at a community hospital. Am J Gastroenterol 1986;81:1171-3.

25. Himal HS, Schumacher S. Endoscopic vs surgical gastrostomy for enteral nutrition. Surg Endosc 1987;1:33-5.

26. Larson DE, Burton DD, Schroeder KW, DiMagno EP. Percutaneous endoscopic gastrostomy: indications, success, complications, and mortality in 314 consecutive patients. Gastroenterology 1987;93:4852.

27. Foutch PG, Talbert GA, Waring JP, Sanowski RA. Percutaneous endoscopic gastrostomy in patients with prior abdominal surgery: virtues of the safe tract. Am J Gastroenterol 1988;83:147-50.

28. Foutch PG, Woods CA, Talbert GA, Sanowski RA. A critical analysis of the Sacks-Vine gastrostomy tube: a review of 120 consecutive procedures. Am J Gastroenterol 1988;83:812-5.

29. Ho CS, Yee AC, McPherson R. Complications of surgical and percutaneous nonendoscopic gastrostomy: review of 233 patients. Gastroenterology 1988;95:1206-10.

30. Kelly KM, Lewis B, Gentili DR, Benjamin E, Waye JD, Iberti TJ. Use of percutaneous gastrostomy in the intensive care patient. Crit Care Med 1988;16: 62-3.

31. Llaneza PP, Menendez AM, Roberts R, Dunn GD. Percutaneous endoscopic gastrostomy: clinical experience and follow-up. South Med J 1988;81:321-4.

32. Stellato TA, Gauderer MW. Percutaneous endo- scopic gastrostomy in the cancer patient. Am Surg 1988;54:419-22.

33. Foutch PG, Talbert GA, Gaines JA, Sanowski RA. The gastrostomy button: a prospective assessment of safety, success, and spectrum of use. Gastrointest Endosc 1989;35:41-4.

34. Miller RE, Castlemain B, Lacqua FJ, Kotler DP. Percutaneous endoscopic gastrostomy: results in $\mathbf{3 1 6}$ patients and review of literature. Surg Endosc 1989;3:186-90.

35. Clarkston WK, Smith OJ, Walden JM. Percutaneous endoscopic gastrostomy and early mortality. South Med J 1990;83:1433-6.

36. Davis JB Jr, Bowden TA Jr, Rives DA. Percutaneous endoscopic gastrostomy. Do surgeons and gastroenterologists get the same results? Am Surg 1990; 56:47-51.

37. George J, Crawford D, Lewis T, Shepherd R, Ward $M$. Percutaneous endoscopic gastrostomy: a twoyear experience. Med J Aust 1990;152:17-9.

38. Hicks ME, Surratt RS, Picus D, Marx MV, Lang EV. Fluoroscopically guided percutaneous gastrostomy and gastroenterostomy: analysis of 158 consecutive cases. AJR Am J Roentgenol 1990;154:725-8.

39. Saini S, Mueller PR, Gaa J, Briggs SE, Hahn PF, Forman BH, et al. Percutaneous gastrostomy with gastropexy: experience in 125 patients. AJR Am J Roentgenol 1990;154:1003-6.

40. Samii AM, Suguitan EA. Comparison of operative gastrostomy with percutaneous endoscopic gastrostomy. Mil Med 1990;155:534-5.

41. Stiegmann GV, Goff JS, Silas D, Pearlman N, Sun J, Norton L. Endoscopic versus operative gastrostomy: final results of a prospective randomized trial. Gastrointest Endosc 1990;36:1-5.

42. Wolfsen HC, Kozarek RA, Ball TJ, Patterson DJ, Botoman VA, Ryan JA. Long-term survival in patients undergoing percutaneous endoscopic gastrostomy and jejunostomy. Am J Gastroenterol 1990; 85:1120-2.

43. Fay DE, Poplausky M, Gruber M, Lance P. Longterm enteral feeding: a retrospective comparison of delivery via percutaneous endoscopic gastrostomy and nasoenteric tubes. Am J Gastroenterol 1991;86: 1604-9.

44. Finucane P, Aslan SM, Duncan D. Percutaneous endoscopic gastrostomy in elderly patients. Postgrad Med J 1991;67:371-3.

45. Horton WL, Colwell DL, Burlon DT. Experience with percutaneous endoscopic gastrotomy in a community hospital. Am J Gastroenterol 1991;86:168-70.

46. Scott JS, de la Torre RA, Unger SW. Comparison of operative versus percutaneous endoscopic gastrostomy tube placement in the elderly. Am Surg 1991; 57:338-40.

47. Deutsch LS, Kannegieter L, Vanson DT, Miller DP, Brandon JC. Simplified percutaneous gastrostomy. Radiology 1992;184:181-3. 
48. Jarnagin WR, Duh QY, Mulvihill SJ, Ridge JA, Schrock TR, Way LW. The efficacy and limitations of percutaneous endoscopic gastrostomy. Arch Surg 1992;127:261-4.

49. Taylor CA, Larson DE, Ballard DJ, Bergstrom LR, Silverstein MD, Zinsmeister AR, et al. Predictors of outcome after percutaneous endoscopic gastrostomy: a community-based study. Mayo Clin Proc 1992;67:1042-9.

50. Hull MA, Rawlings J, Murray FE, Field J, McIntyre AS, Mahida YR, et al. Audit of outcome of longterm enteral nutrition by percutaneous endoscopic gastrostomy. Lancet 1993;341:869-72.

51. Olson DL, Krubsack AJ, Stewart ET. Percutaneous enteral alimentation: gastrostomy versus gastrojejunostomy. Radiology 1993;187:105-8.

52. Stuart SP, Tiley EH 3d, Boland JP. Feeding gastrostomy: a critical review of its indication and mortality rate. South Med J 1993;86:169-72.

53. Edelman DS, Arroyo PJ, Unger SW. Laparoscopic gastrostomy versus percutaneous endoscopic gastrostomy. A comparison. Surg Endosc 1994;8:47-9.

54. Kaw M, Sekas G. Long-term follow-up of consequences of percutaneous endoscopic gastrostomy (PEG) in nursing home patients. Dig Dis Sci 1994;39:738-43.

55. Laing B, Smithers M, Harper J. Percutaneous fluoroscopic gastrostomy: a safe option? Med J Aust 1994;161:308-10.

56. McLoughlin RF, Gibney RG. Fluoroscopically guided percutaneous gastrostomy: tube function and malfunction. Abdom Imaging 1994;19:195-200.

57. Raha SK, Woodhouse $\mathrm{K}$. The use of percutaneous endoscopic gastrostomy (PEG) in 161 consecutive elderly patients. Age Ageing 1994;23:162-3.

58. Rosenzweig TB, Palestrant AM, Esplin CA, Gilsdorf RB. A method for radiologic-assisted gastrostomy when percutaneous endoscopic gastrostomy is contraindicated. Am J Surg 1994;168:587-91.

59. Bergstrom LR, Larson DE, Zinsmeister AR, Sarr $M G$, Silverstein MD. Utilization and outcomes of surgical gastrostomies and jejunostomies in an era of percutaneous endoscopic gastrostomy: a populationbased study. Mayo Clin Proc 1995;70:829-36.

60. Kohli H, Bloch R. Percutaneous endoscopic gastrostomy: a community hospital experience. Am Surg 1995;61:191-4.

61. Light VL, Slezak FA, Porter JA, Gerson LW, McCord G. Predictive factors for early mortality after percutaneous endoscopy gastrostomy. Gastrointest Endose 1995;42:330-5.

62. Choudhry U, Barde CJ, Markert R, Gopalswamy N. Percutaneous endoscopic gastrostomy: a randomized prospective comparison of early and delayed feeding. Gastrointest Endosc 1996;44:164-7.

63. Elliott LA, Sheridan MB, Denyer M, Chapman AH.
PEG - is the E necessary? A comparison of percutaneous and endoscopic gastrostomy. Clin Radiol 1996;51:341-4.

64. Rabeneck L, Wray NP, Petersen NJ. Long-term outcomes of patients receiving percutaneous endoscopic gastrostomy tubes. J Gen Intern Med 1996;11:287-93.

65. Ryan JM, Hahn PF, Boland GW, McDowell RK, Saini S, Mueller PR. Percutaneous gastrostomy with T-fastener gastropexy: results of 316 consecutive procedures. Radiology 1997;203:496-500.

66. Elixhauser A, Harris DR, Coffey RM. Trends in hospital procedures performed on black patients and white patients: 1980-87. Provider Studies Research Note 20. Rockville, Md: Agency for Health Care Policy and Research, Center for General Health Services Intramural Research, Public Health Service, 1994. (AHCPR publication no. 94-0003.)

67. Gaines K, Burke G. Ethnic differences in stroke: black-white differences in the United States population. SECORDS Investigators. Southeastern Consortium on Racial Differences in Stroke. Neuroepidemiology 1995;14:209-39.

68. Caralis PV, Davis B, Wright K, Marcial E. The influence of ethnicity and race on attitudes toward advanced directives, life-prolonging treatments, and euthanasia. J Clin Ethics 1993;4:155-65.

69. Kozak LJ. Underreporting of race in the National Hospital Discharge Survey. Advance data from vital and health statistics; no. 265. Hyattsville, Md: Public Health Service, Centers for Disease Control and Prevention, National Center for Health Statistics. 1995. (DHHS publication no [PHS] 95-1250.)

70. Fisher ES, Whaley FS, Krushat WM, Malenka DJ, Fleming C, Baron JA et al. The accuracy of Medicare's hospital claims data: progress has been made, but problems remain. Am J Public Health 1992;82: 243-8.

71. Tatemichi TK, Desmond DW, Mayeux R, Paik M, Stern Y, Sano M, et al. Dementia after stroke: baseline frequency, risks, and clinical features in a hospitalized cohort. Neurology 1992;42:1185-93.

72. Mowe $M$, Bohmer T. The prevalence of undiagnosed protein-calorie undernutrition in a population of hospitalized elderly patients. J Am Geriatr Soc 1991;39:1089-92.

73. Burtch GD, Shatney CH. Feeding gastrostomy. Assistant or assassin? Am Surg 1985;51:204-7.

74. Baeten CB, Hoefnagels J. Feeding via nasogastric tube or percutaneous endoscopic gastrostomy. A comparison. Scand J Gastroenterol Suppl 1992;194:95-8.

75. Weltz CR, Morris JB, Mullen JL. Surgical jejunostomy in aspiration risk patients. Ann Surg 1992;215: 140-5.

76. Raha SK, Woodhouse KW. Who should have a PEG? Age Ageing 1993;22:313-5. 